human migrations, including an early phase of hunter-gatherer expansion around 40,000 years ago, and a later phase of population intrusion by Austronesian speakers about 3,500 years ago - reflected archaeologically in the Lapita cultural complex. This latter intrusion resulted in virtually all island Melanesian populations speaking Oceanic languages (a branch of Austronesian).

Other regional specialists will doubtless find similar problems with Cavalli-Sforza's efforts to correlate genes and languages at such a broad level. But this does not mean that the effort to construct such worldwide correlations is futile, for there is clearly much historical truth in Cavalli-Sforza's models. As a first approximation, the history of human diasporas painted in this book shows a vast improvement in our knowledge, which has been made possible by rapid advances in method. And not just in biological science, for the historical linguists themselves are now tackling the thorny issues of deep-time language reconstruction more intensively than ever before. My point is simply that Cavalli-Sforza's models will need more work, and much refinement, before they will satisfy all the critics.

In his final chapter Cavalli-Sforza ranges widely over some of the most profound questions of human evolution, including the role of culture as a means of biological evolution, the modes by which culture is transmitted, and the emergence of complex hierarchical social structures. The ideas raised here reinforce how essential it is for social scientists and biologists not to be isolated - as they so often are in the intellectual structures of modern academia - and to realize how much they need each others' insights.

Edward Sapir eloquently laid out a multidisciplinary methodology for historical reconstruction in his now little-read 1916 monograph Time Perspective in Aboriginal American Culture: A Study in Method (Canada Department of Mines). At the time, the most sophisticated discipline contributing to the tracing of deep-time human history was linguistics. Sapir himself lamented that he had probably "undervalued the data of physical anthropology". Little could he have anticipated the advances that would come with the revolution in molecular biology and genetics.

Cavalli-Sforza and his colleagues have now given historical anthropology sophisticated tools to look at human variation, and to read that variation as a 'text' of human history. Cavalli-Sforza writes that "to some, history is not a science", but he has helped to show that history is susceptible both to the methods of science and to the power of a multidisciplinary approach.

Patrick V. Kirch is at the P. A. Hearst Museum of Anthropology, University of California, 103 Kroeber Hall, Berkeley, California

94720-3712, USA.

\section{Evolution in a broader perspective}

\section{Lucy's Legacy: Sex and \\ Intelligence in Human Evolution} by Alison Jolly

Harvard University Press: 1999. 518 pp.

$\$ 29.95, £ 18.50$

\section{Christophe Boesch}

Gigolo in French means a male prostitute, while in German it may mean a Don Juan, and some Americans see in it a man used by women in one way or another. Alison Jolly probably had this last sense in mind when she provocatively proposed to rename a group of primates with many females and a single male a 'gigolo' group. The alternative term 'harem' suggests that it is the male who is most important; if he's a gigolo, he's there because the females tolerate him.

Alison Jolly's book is a refreshing and stimulating account of evolution, and especially of the evolution of sex and intelligence in humans and primates. One of its strengths is her presentation of the female view. We men have always had a tendency to consider life mainly from our own perspective. Thus, terms such as 'female choice' or 'female control' rapidly faded out of favour despite the fact that Darwin used them. But it is important for men to consider the other view of evolution, sex and intelligence - especially since there are good theoretical reasons to expect that intelligence can out-compete strength, and that internal fertilization gives every female mammal the final choice of which sperm is going to fertilise her egg. It would be surprising if females did not use this huge advantage.

Jolly proposes that the traditional feminine viewpoint on evolution is one of cooperative organization and not of competition. This is a counterpart to the fundamental dilemma for anyone trained in Darwinian evolutionary theory, with its emphasis on rampant individualism: how did society develop in the face of this? For her, "selfish

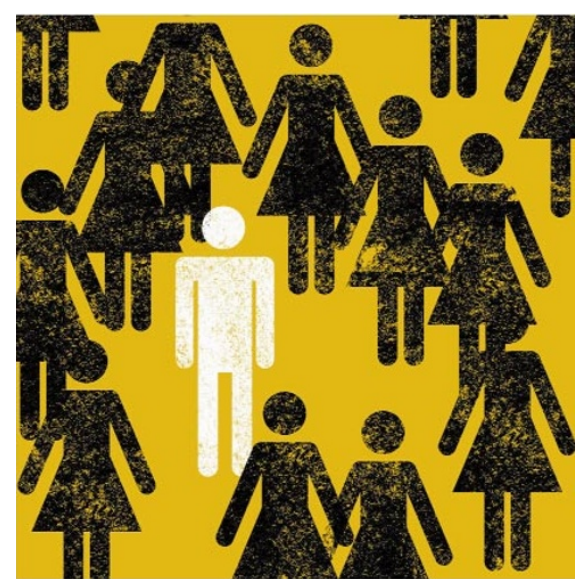

genes, interacting with their environment, led to love between kin, trust between friends, the intricacies of the mind, and the emergent organisations of society".

Jolly tells the story from her own perspective as a woman, teacher and lemur-watcher, taking examples from women's lives such as female orgasm, menstruation, childbearing and menopause. Some of these stories are quite illuminating. To explain to sceptics that not all human behaviour is either learned or conscious, she takes the example of labour. "Your body, willy-nilly, starts to sneeze, goes into labour, opts to move from first- to second-stage contractions. A nurse told me once, 'Don't you dare push!' 'I'm not pushing!' I squawked, 'It is!' ... the body's wisdom during labour does not rest on your conscious decisions."

Obviously only men could propose in face of such evidence that human behaviour is a tabula rasa! The only regret I have is that her case for showing that evolution is as much about cooperation as about competition is not convincingly presented. Obviously cells in the same organism must cooperate, otherwise they would commit suicide. But individuals do compete regularly and Jolly does not present adequate evidence for cooperation.

A good case could have been presented about sex. Do males and females cooperate or compete? While commenting that "politically correct biologists try hard to describe sex as cooperation between equal partners", Jolly presents evidence of both competition and cooperation. In the course of evolution, the two sexes have differentiated in such a way that they depend on one another, so that sex does not work without at least some cooperation. But for readers who fear that biologists might apply what we observe in animals to human beings, she rightly says of observed instances of violence and killing in animals that "what is natural is not necessarily right", leading the way to more philosophical questions. As debate rages about the existence of 'moral' actions in animals, she tells us that, for some people, "it seemed immoral that morality should increase genetic fitness".

In other words, this book is a quest for a better understanding of human evolution and a challenging contribution to the debate about human uniqueness, if this does indeed exist. I strongly recommend it to those who are new to the field because of the breadth of the topics and the clarity with which they are presented. To those working in the field I strongly recommend it for the new approach Alison Jolly takes to some of those questions. She suggests that beside concealment of ovulation in women, what is new in human sex is the general need for privacy. But I'll leave readers to discuss that for themselves.

Christophe Boesch is at the Max Planck Institute for Evolutionary Anthropology, Inselstrasse 22, 04013 Leipzig, Germany. 